\title{
POETRY
}

\section{On diagnosing Alzheimer dementia}

I'm telling you what you cannot understand. I wonder if we are lost, or merely waylaid; where the ultimate question, and your smile belie years receding into perfection.

I said the diagnosis as if there were sense to be made, meanwhile there was your husband who said I'm dying inside. Self-diagnosis always makes my job easier. I look at you, who can still command appearances, who have not yet receded from the human.

Did you know that, at the end, you may lose your smile? You will only have a few months to live then. Poets know this. Doctors sign the death certificate. When it is not up to us, you and me, I'm afraid. Your husband looks at me with forethought.

You are smiling and social, a perfect acquaintance at a party. And that there are drugs seems an afterthought. Much is after, D-day, and the before is taking care of itself in an Elysian field, or developing in a darkroom, or nowhere.

Do not remember me, or what I say: Look at your husband $\sim$ in the dementia of meaning. There are still allotments.

Take heed of what is left, build a life raft for goodbye, and when we cease to love, there is time to forget.

Shane Neilson MD

Family physician

Guelph, Ont.

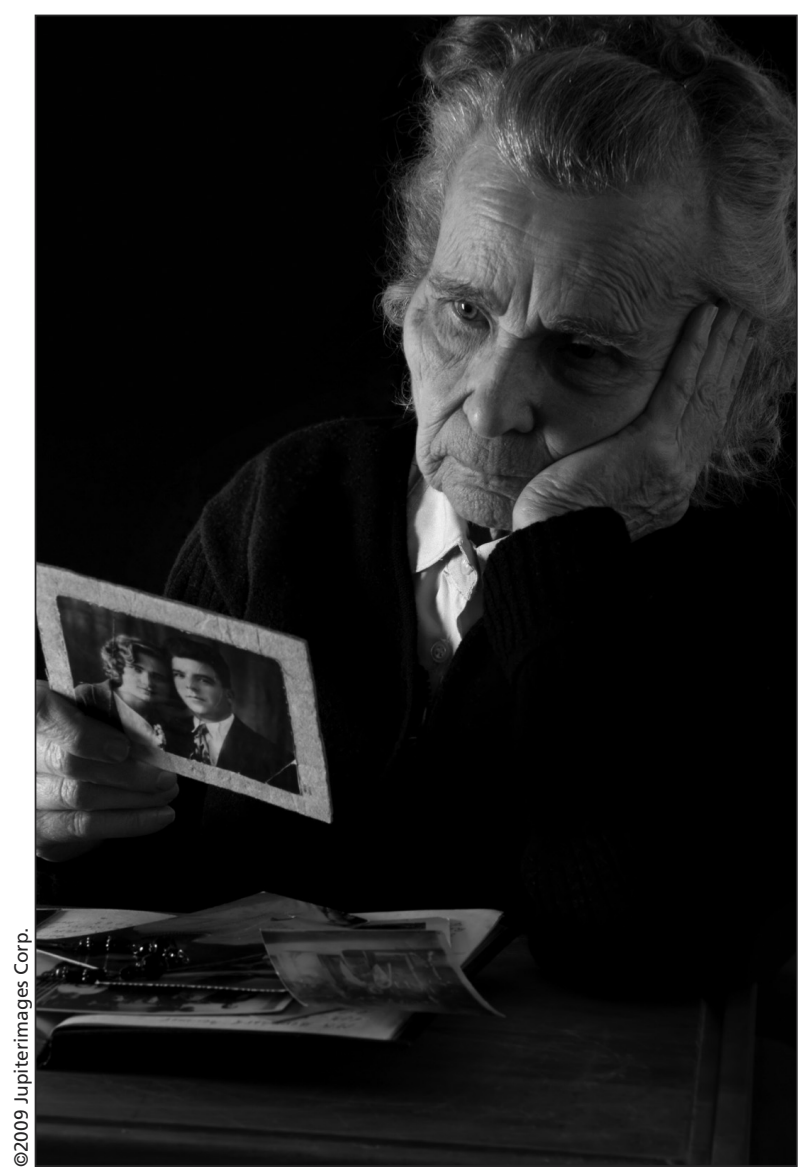

